\title{
Note on Texts
}

This book refers to Gayatri Chakravorty Spivak's English translation of Jacques Derrida's Of Grammatology in the first instance, because this is the version of the text that the vast majority of anglophone readers will be using. However, I follow each reference to the English translation with the corresponding reference to the original French text, so that interested readers may chase this up if they so wish. In general, then, page references to Derrida's text will take the following form: Grammatology, p. 214/308. 
